\title{
Use of Probiotics in Diets of Tilapia
}

\section{Thomas L. Welker ${ }^{1 *}$ and Chhorn Lim²}

${ }^{1}$ Agricultural Research Service, United States Department of Agriculture, Hagerman Fish Culture Station, 3059F National Fish Hatchery Road, Hagerman, ID, USA

${ }^{2}$ Agricultural Research Service, United States Department of Agriculture, Aquatic Animal Health Research Unit, 990 Wire Road, Auburn, AL 36832, USA

\begin{abstract}
Aquaculture is one of the fastest growing sectors of agriculture globally. Production in freshwater and marine fisheries has plateaued, and the increasing demand for seafood and need for affordable protein sources in third world countries will ensure growth of aquaculture in the future. Tilapia are the second most cultured fish worldwide behind the carps, and even though they are easily cultured in a wide variety of environments and are relatively resistant to aquaculture stressors compared to other cultured finfish species, significant losses to disease still occur under intensive culture. Traditionally, antibiotics and other chemicals have been used to treat disease outbreaks in cultured fish species. However, the scope of approved application for most antibiotics is very narrow and concern over development of antibiotic resistant pathogens will further limit use in the future. The focus instead has turned to finding safe and effective means of preventing infectious diseases in cultured finfish, including tilapia. In recent years, there has been considerable interest in the use of probiotic bacteria added to diets to increase immunity as well as improve growth performance in fish. Little probiotic research has been conducted in tilapia, but of the research that has been performed, most has taken place within the last five years. Due to its apparent effectiveness in improving health and growth in tilapia, research and interest in probiotics is likely to continue, which will hopefully fill existing research gaps.
\end{abstract}

\section{Introduction}

Tilapia, because of their enormous adaptability to a wide range of physical and environmental conditions, ability to reproduce in captivity, relative resistance to handling stress and disease-causing agents compared to other cultured finfish species, good flesh quality, feed on a low trophic level and excellent growth rate on a wide variety of natural and artificial diets, are the most abundantly cultured species worldwide. Although they are endemic to tropical freshwater in Africa, Jordan and Israel, their distribution has widened following introductions to other regions of the world in the early part and after the middle of the $20^{\text {th }}$ century. They are presently cultured in virtually all types of production systems, in both fresh and salt water, and in tropical, subtropical and temperate climates [1]. Tilapia dominate both small- and large-scale aquaculture in many tropical and subtropical countries, both as low-price commodity for mass consumption as a staple protein source and as a high-value, upscale product for export markets. They are the second most cultured freshwater fish in the world (after carps). However, they are increasingly recognized as the species of choice for intensive aquaculture and are likely to become the most important cultured fish in the world [2]. According to the American Tilapia Association, global farm-raised tilapia production is expected to reach 3 million metric tons by 2010, compared to 2.6 million metric tons in 2007. Several species of tilapia are being cultured commercially, but Nile tilapia, Oreochromis niloticus and various hybrids are the predominant culture species worldwide.

A major problem associated with intensive fish culture operations is the increased susceptibility of fish to infectious diseases. The total losses from disease outbreaks in aquaculture worldwide have reached billions of dollars annually and have been identified as a major threat to the sustainability of aquaculture industry. Traditionally, antibiotics and chemicals have been used to treat diseases in aquatic animals [3]. However, given the fact that diseased fish eat poorly, a limited number of government-approved and efficacious drugs/chemicals are available, and the increasing problem of emerging drug-resistant pathogens and the resultant food and environmental contamination [4], disease prevention, rather than treatment of sick fish, is a better means of controlling infectious diseases. Moreover, the use of antibiotics in animal production, including aquaculture, is increasingly under public scrutiny and criticism in most developed countries. Consequently, there have been considerable interests in recent years to evaluate the feasibility of using non-nutrient dietary additives, particularly prebiotics and probiotics, to enhance growth, stimulate immune system function and/or improve the resistance of fish to infectious diseases. Numerous reviews on these subjects have been published in the past decade [512]. Although most research has focused on dietary supplementation of probiotics, other means of administration have also been used, e.g. by addition to rearing water [13].

This chapter provides an overview on the use of probiotics in diets and their effects on growth performance, feed utilization efficiency, gut microbiota, immune responses, and disease resistance of tilapia.

\section{Overview and definitions}

Considerable attention has been given to alteration of the gut microbiota to boost health in humans and other animals in recent years through the use of probiotics and prebiotics (termed biotics). The goal of these dietary supplements is similar, but the manner in which they alter the gut microbial community is varied. Furthermore, some of the probiotic and prebiotic products are similar in composition, containing inactivated microbes or microbial components, which has led to some confusion over what exactly constitutes a "probiotic" or a "prebiotic". The definitions of probiotic and prebiotic have changed to some degree since both terms were first introduced. The most widely used

*Corresponding author: Thomas L. Welker, Agricultural Research Service, United States Department of Agriculture, Hagerman Fish Culture Station, 3059F National Fish Hatchery Road, Hagerman, ID, USA, E-mail: thomas.welker@ars.usda.gov

Received August 04, 2011; Accepted November 21, 2011; Published November 30, 2011

Citation: Welker TL, Lim C (2011) Use of Probiotics in Diets of Tilapia. J Aquac Res Development S1:014. doi:10.4172/2155-9546.S1-014

Copyright: @ 2011 Welker TL, et al. This is an open-access article distributed unde the terms of the Creative Commons Attribution License, which permits unrestricted use, distribution, and reproduction in any medium, provided the original author and source are credited. 
definition of probiotics is given by Fuller [14] as "a live microbial feed supplement which beneficially affects the host animal by improving intestinal balance". Current probiotic applications and scientific data on mechanisms of action indicate that non-viable microbial components act in a beneficial manner, and this benefit is not limited to the intestinal region [9], indicating that probiotics may include non-viable microbes and gut colonization is not necessary to produce benefits to the host. There is some debate as to whether the commonly accepted definition should be revised to include these changes. However, for the purposes of this review, living microorganisms, for the most part, will be considered as probionts. Prebiotics, on the other hand, are any non-digestible food ingredient that beneficially affects the host by selectively stimulating the growth and/or activity of one or a limited number of bacteria in the colon [12]. Synbiotics, a relatively recent concept, may prove more effective in controlling the microbiota of the gastrointestinal (GI) tract [8]. Synbiotics are supplements that contain both prebiotics and probiotics. An effective synbiotic pairing would allow alteration of the colonic environment by a prebiotic that would select for preferential growth conditions of known beneficial probionts. The benefits of this approach are obvious: fish culturists not only are able to control and provide favorable conditions in the colon but also ensure that a beneficial probiont is present in sufficient numbers.

As has been pointed out by numerous researchers $[8,9,11,15-$ 17], there is an increasing need to find safe alternatives to antibiotics. Intensive fish culture increases the prevalence of stress-related disease outbreaks and associated fish losses. Traditional use of antibiotics to prevent disease in fish has received criticism due to the potential for development of antibiotic resistant bacteria, the presence of antibiotic residues in fish tissue, negative impacts on microbial populations in the aquaculture environment, and suppression of the cultured species' immune system $[12,15]$. Probiotics have received the most attention as a viable alternative; however, their use poses a number of potential drawbacks: possible negative impact of untested probionts on the environment, regulatory constraints, food safety issues, and maintaining viable probionts through the feed manufacturing process (particularly extrusion) [18]. Use of bacterial species known to be safe for humans and the environment may be the most expedient approach for testing of prospective probionts and maintaining viable populations during storage [8]. Although there are a number of drawbacks to implementation of probiotics in fish diets, when used properly, they can be effective in improving growth performance and immunity in tilapia.

The study of the effects of probiotics supplemented in the diet of tilapia has not advanced as far as it has in other species, such as salmonids. Merrifield et al. [11] provide an excellent and detailed review of the status of biotics in salmonids. By comparison, the available research with tilapia is severely lacking, underscoring that more research is required. However, research on the supplementation of probiotics in the diets of tilapia is advancing rapidly with the majority of studies taking place since the mid-2000s, and further advances are likely to occur in the coming years.

\section{Types of probionts}

There are generally two choices when selecting a probiont to supplement in diets of fish: 1) bacteria native to and isolated from the host fish species and 2) commercially available probionts typically of non-fish origin (the majority sold for use in terrestrial animals). The first choice may be the most sensible and potentially successful, since they are capable of colonizing the intestinal epithelial surface and grow within the intestinal mucus, are able to survive the pre-colon digestive tract environment of the host species, are not pathogenic to the host, and are likely environmentally safe. However, for most prospective probionts isolated from fish there are questions about potential safety issues and effectiveness as a probiotic, for example: it is unknown whether they are free of plasma-encoded antibiotic resistance genes, pose a potential health risk to humans and other animals, possess desirable growth characteristics, are easily cultured, and remain viable under normal storage conditions and after the feed making process [11]. The cost of undertaking the regulatory approval process for these indigenous species may prove to be a major obstacle for commercialization [8]. More familiar microorganisms, already tested in other animal species with a body of knowledge supporting their safe use presents a substantial advantage for approval, and many of these probiont species are already available in commercial preparations. Likewise, microorganisms isolated from the gut of fish but belonging to familiar groups (Bacillus spp., Lactobacillus spp., yeast spp, and others) may also be suitable $[8,11]$.

\section{Gut Microbiota and Probiotics}

Much more is known about the microbiota of the GI tract in mammals and its role in mammalian health compared to fish, but in recent years, substantial research has been conducted to characterize the gut microbiota of fish [17]. The GI microbiota perform a variety of functions that benefit the health of the host species by promoting nutrient supply, enhancing immune function, preventing colonization of pathogenic microbes, energy homeostasis, and maintenance of normal mucosal integrity and function. However, little is known about bacterial communities, their establishment and diversity, and role in fish nutrition and health. In tilapia, early work focused on describing the gut microbiota in naturally-occurring populations and cultured fish in Japan [19-25] and only later investigations have centered more on changes in the gut microbial community and health effects through the use of probiotics.

\section{Microbial community of the tilapia GI tract}

Few studies have characterized the microbial composition of the GI tract of tilapia. The majority of those studies were conducted by Sugita and colleagues in the 1980s using traditional microbiological culture methods. Even more recent examinations of tilapia gut microbiota have continued to rely on traditional culture techniques, rather than more reliable and advanced molecular identification methods. Under normal conditions, the dominant microbial species in the intestine of fish are anaerobic (e.g., Bacillus, Bifidobacterium, Lactobacillus, Saccharomycetes, etc.) accounting for $99 \%$ of the microbial community; aerobic and facultative bacteria only account for $1 \%$ of the population [15]. Facultative anaerobic bacteria from the Vibrio-Aeromonas group and obligate anaerobic bacteria, Bacteroides type A and type B [19,21], Plesiomonas shigelloides, A. hydrophila [24], and Cetobacterium somerae [26] are the primary bacteria comprising the GI tract of cultured Nile tilapia. Sugita et al. [22] found the microbiota in freshwater cultured tilapia to be rather stable. However, the rearing environment of tilapia can cause shifts in the gut microbial composition. Obligate anaerobes declined and were replaced by aerobic and facultatively anaerobic Gram negative rods (Vibrio-Aeromonas group) when tilapia were adapted from freshwater to seawater [21]. The authors suggest that dominance of the GI microbiota by Bacteroides type A and type B is restricted to fish cultured in freshwater. The effect of the salinity of the rearing environment on the intestinal microbiota of tilapia is also illustrated by examining the research of Al-Harbi and Uddin (27-29). Gut bacteria in Nile tilapia cultured in brackish water were dominated by Vibrio spp. 
[29], while tilapia reared in freshwater, earthen ponds exhibited a greater diversity of gut bacteria, predominately comprised of Gram-negative rods (Aeromonas hydrophila, Shewanella putrefaciens, Corynebacterium urealyticum, E. coli, and Vibrio cholera) [27,28]. In these studies, the gut bacterial population correlated well with the predominant species found in the rearing water and pond sediment, showing that the rearing environment plays a large role in the gut microbial composition. Sugita et al. [23] also suggests that the predominant bacterial species in tilapia GI tract, including aerobes and anaerobes, originate from the culture environment. Molinari et al. [30] reported that the GI tract of Nile tilapia is dominated by eight bacterial species, Aeromonas veronii, A. hydrophila, Burkholderia cepacia, Chromobacterium violaceum, Citrobacter freundii, E. coli, Flavimonas zryzihabitans, and Plesiomonas shgelloides. Although some of these species are also dominant in work by Sugita et al. and Al-Harbi and Uddin, the differences, which are likely affected to some degree by isolation and identification methods (especially the lack of strict anaerobic isolation methods by Al-Harbi and Uddin and Molinari et al. [28]), also suggest the rearing environment should be taken into consideration when selecting probionts for supplementation in diets of tilapia.

Gut microbial composition can also vary seasonally and with changes in diet. Al-Harbi and Uddin [28] discovered that the bacterial composition of tilapia gut can fluctuate considerably depending on the time of year. Even with the most dominant bacterial species, numbers (total counts and as a percentage of the total population) change dramatically during the course of a year. Modifications of diet can also affect the microbiota composition. In rainbow trout, the gut microbiota make-up is altered when fish were switched from a fish meal to a plant meal based diet [31]. With continued emphasis on use of alternative feed ingredients in place of fish meal and fish oil, many currently used probiotics may prove ineffective with changes in diet formulation. However, probiotic applications proven successful in improving growth with traditional fish meal-based diets may also improve digestibility and utilization of alternative plant ingredients. Use of established probiotics may need to be re-evaluated with alterations in diet and rearing conditions, and selection of new probionts and/or development of new feeding regimes may be required.

\section{Changes in gut microbiota}

Although a number of studies have been conducted which examine the effect of dietary probiotics on tilapia health, only a few have determined the impacts of supplementation on the microbiota of the GI tract. The aim of probiotic use is to alter the gut microbial composition. The normal microbiota of the tilapia GI tract is established 20 to 60 days after hatching [22]. After the microbiota is established, modifying the microbial composition of the gut is complicated/complex, further complicated by several exogenous and endogenous factors that can also influence establishment or alteration of the GI tract microbiota of fish. Gut structure, rearing environment, and farming practices can all effect initial colonization and establishment [17]. The goal of probiotic supplementation (immune stimulation, disease resistance, growth performance, etc.) must also be taken into account [11]. Therefore, proper selection of probionts is critical to success, and as mentioned, use of more than one species or type of probiont in diet may be wise to ensure success with changing conditions and developmental stage, which has proven to be effective in mammals [32] but remains largely untested in fish.

Establishing the effects of probiotic dietary supplementation on the indigenous microbial population of fish has been difficult because researchers have predominantly enumerated the GI microbial population after probiotic supplementation with little attention paid to the composition of the indigenous microbiota [11]. This observation also holds true for tilapia, but a few studies have attempted to characterize the GI tract microbial make-up. Nile tilapia fed diets supplemented with viable Saccharomyces cerevisiae + Bacillus subtillus or non-viable S. cerevisiae produced different GI tract microbial compositions [33]. Tilapia fed non-viable $S$. cerevisiae showed no change in the intestinal microbial community, which was dominated by E. coli, Salmonella spp., Klebsiella spp., Morganella morganii, E. tarda, Aeromonas sobria, and P. fluorescens. Tilapia fed the diet supplemented with the viable yeast + B. subtillus mixture showed no presence of E. coli, Salmonella spp., Klebsiella spp., or P. fluorescens. Nile tilapia fed diets supplemented with Pediococcus acidilactici exhibited alteration of the indigenous gut bacterial population [34] (this is the only study which has examined the effects of probiotic supplementation on the gut microbiota in tilapia using a molecular, culture independent method). Although the total counts of aerobes and anaerobes did not change, lactic acid bacteria increased significantly in tilapia fed the probiont. P. acidilactici persisted in the gut of Nile tilapia for seventeen days after fish reverted to the control diet. $P$. acidilactici also provided antagonism against an unidentified bacterium. Knowledge on the impact of probiotic supplementation on the indigenous gut microbiota in tilapia and other species is lacking - this information is important to understanding which microbial species are best suited for dietary supplementation and how they may affect fish health.

\section{Physiological Changes and Growth Performance}

A number of specific modes of action by probiotic microorganisms has been attributed to physiological benefits in fish. Although gut colonization is often identified as the most important characteristic of effective probionts, the reality is that the benefits incurred by the host from probiotic supplementation are likely a synergistic product of multiple biological effects (some of which have nothing to do with gut colonization), including production of inhibitory compounds, competition for chemicals or available energy, competition for adhesion sites, inhibition of virulence gene expression or disruption of quorum sensing, enhancement of the immune response, source of macro and/or micronutrients, enzymatic contribution to digestion, and stimulation of local and systemic immune responses [11]. Identifying the specific effect(s) produced by probionts that benefit fish can prove difficult. However, such benefits have been documented in many fish species, including tilapia, some of which will be expanded on in this manuscript.

\section{Changes in gastrointestinal morphology}

The endogenous microbiota of the GI tract also affects GI morphology and function of fish. Gnotobiotic studies (animals cultured under axenic conditions) in fish have shown that the GI microbiota community is important in nutrient metabolism and absorption, regulation and energy balance, development and maturation of the mucosal immune system, and epithelial differentiation and maturation [17]. In zebrafish, the absence of GI microbiota results in arrestment of the gut epithelium from a lack of brushborder intestinal alkaline phosphatase activity [35]. The authors also found that proliferation of goblet cells, enteroendocrine cells, and other secretory cell lines are tied to gut microbiota. Maintenance of a healthy gut microbiota is a likely benefit to the development of the gut epithelial architecture, and because many fish pathogens can disrupt the integrity of the intestinal epithelium, a healthy GI microbial population may reduce mucosal damage, increase absorptive area, and prevent pathogenic disease [11]. Few studies have examined the effects of probionts on 
intestinal morphology of tilapia. Ferguson et al. [32] found no effect on intestinal morphology when tilapia were fed diets supplemented with $\mathrm{P}$. acidilactici. Pirarat et al. [36] discovered that dietary supplementation of $L$. rhamnosus promoted the development of the intestinal structure of Nile tilapia. Fish fed the probiotic diet had greater villous height in the proximal and middle sections of the intestine. Similar results were found by Merrifield et al. [37] in rainbow trout, where dietary supplementation with $P$. acidilactici increase microvilli length but not density in the proximal intestine. More research is needed in tilapia and other species to determine the mechanisms by which probiotic microorganisms affect gastrointestinal morphology.

\section{Nutrient utilization, digestion, and growth}

The gut microbial population is also important to the nutrition of fish by increasing nutrient uptake and utilization, production of enzymes, amino acids, short-chain fatty acids, and vitamins, and improved digestion [11,17]. Lovell and Limsuwan [38] found that the intestinal microbiota of Nile tilapia fed a $B_{12}$ deficient diet were able to produce at least $11.2 \mathrm{ng}$ vitamin $\mathrm{B}_{12} / \mathrm{g}$ body weight per day, almost ten times that of channel catfish. Sugita et al. $[39,40]$ reported that obligate anaerobes, primarily Bacteroides type A and Clostridium spp., were likely responsible for vitamin $B_{12}$ production in the gut of tilapia. Tsuchiya et al. [1] also found that 17 strains of Bacteroides type A isolated from the gut of tilapia were able to synthesize vitamin $B_{12}$ at a rate of approximately $8 \mathrm{ng} / \mathrm{mL}$ culture in $48 \mathrm{hr}$. Tilapia do not require vitamin $B_{12}$ supplementation in diets to prevent deficiency because of the microbial vitamin $B_{12}$ production capability of the gut microbial community. Other B vitamins (nicotinic acid and pantothenic acid) are also produced by intestinal bacteria of fish [41], although it is undocumented whether the same is true for tilapia. Production of other fat or water soluble vitamins by microorganisms in the GI tract of fish has not been reported.

Few studies have examined the impact of probiotics on nutrient uptake and utilization in fish, including tilapia. However, there are reports of improved nutrient utilization through probiotic use in tilapia and other species of fish. Rainbow trout exhibited relief from vertebral column compression syndrome due to improved bone formation/mineral utilization from improved mineral uptake in fish fed diets containing the probiotic $P$. acidilactici $[37,42]$. The authors hypothesize that improved mineral uptake may have been caused by acidification of the intestinal environment through short-chain fatty acid and lactic acid production by the supplemented probionts. No evidence has been reported supporting improved mineral uptake in tilapia through probiotic use, but probiont-assisted production and utilization of other nutrients has been observed. Premalac ${ }^{\bullet}$ or Biogen ${ }^{\circ}$, commercially available probiotic mixtures, supplemented in diets containing varying levels of protein, produced better growth performance in tilapia, suggesting improved protein utilization [43]. Tilapia fed the probiotic diet containing lower dietary protein $(27.5 \%)$ had better growth than fish fed a 30\% protein diet without probiotics. No explanation on the mechanism responsible for the improved protein utilization is provided, but bacteria, including Aeromonads commonly found in the gut of tilapia are known to produce proteases [17]. Gut microbes produce amino acids that are utilized by tilapia. Newsome et al. [44] found that tilapia appeared to be able to acquire their essential amino acid requirements directly from the GI microbiota when dietary sources were insufficient. Volatile, short-chain fatty acids can be produced from anaerobic microbes in the gut of tilapia by fermentation of dietary carbohydrates $[45,46]$. The evidence shows that symbiotic gut microbes in tilapia contribute to nutrient production, and this contribution may be fairly substantial, especially when nutrient requirements are not being fully met by the diet. However, the role of probiotics in the synthesis and/or utilization of most vitamins, minerals, and macronutrients in finfish, including tilapia, are yet unexplored, and future research should emphasize their contribution to physiological maintenance, homeostasis, and growth.

Probiotics may improve digestion by stimulating production of digestive enzymes or through other alterations in the gut environment, which could translate to improved growth performance. Enzymes involved in digestion (carbohydrases, phosphatases, esterases, lipases, peptidases, cellulases, and proteases) are produced by gut microbes in fish, including some species commonly used as probiotics [17]. Amylase, lipase, and protease production was enhanced in tilapia fed diets containing Bacillus subtilis and an unidentified "photosynthetic bacteria" [47]. The author attributes improved weight gain and feed efficiency to the increased enzyme production. Essa et al. [48] also reported improved growth performance of Nile tilapia fed either B. subtilis, Lactobacillus plantarum, a mixture of B. subtillis and L. plantarum, or S. cerevisiae. Fish fed the bacterial probionts, alone or in mixture, showed improved activity of amylase, protease, and lipase enzymes in the GI tract. Tilapia fed the diet containing S. cerevisiae exhibited enhanced amylase but not protease and lipase activities. Streptococcus faecium + Lactobacillus acidophilus or S. cerevisiae supplementation produced significantly higher weight gain and feed utilization efficiency in tilapia fed diets containing $27 \%$ or $40 \%$ crude protein compared to the control diet [49,50]. Disaccharidase but not peptidase activity increased in tilapia fed the probiotic supplemented diets. Fish fed the diet containing $S$. cerevisiae exhibited the greatest increase in growth performance, which was attributed to significantly higher activity of alkaline phosphatase. The authors suggest that the increase in alkaline phosphatase activity reflects the development of brush border membranes of enterocytes stimulated by the supplemented yeast. Activity of the brush border enzymes [51] and alkaline phosphatase [52] can indicate increased nutrient uptake, especially carbohydrate and lipid.

Improved growth performance in tilapia fed probiotic diets has been reported by many researchers (Table 1 included as supplementary data). Tilapia fed S. cerevisiae $[49,50]$, B. subtilis + S. cerevisiae [33,49,50], Micrococcus luteus [53], Bacillus subtilus, Lactobacillus plantarum, B. subtilis + L. plantarum, [48], Bacillus pumilus [54], Lactobacillus acidophilus, Streptococcus faecium [49,50], the commercial probiotic mixtures Organic Green ${ }^{\star}$ [55], Biogen ${ }^{\oplus}$ [43,56,57], and Premalac ${ }^{\oplus}$ [43] have all shown to increase growth performance in tilapia. However, other researchers report no effect of some dietary probiotics on growth. Non-viable S. cerevisiae [33], Pseudomonas spp. [53], Pediococcus acidilactici [34], and Enterococcus faecium (Biomate SF- $\left.20^{\circ}\right)$, B. subtilis + B. licheniformis (Bioplus $2 \mathrm{~B}^{\circ}$ ), and $P$. acidilactici (Bactocell PA10 MD ${ }^{\circ}$ ), viable S. cerevisiae (Levucell SB 20 $0^{\circ}$ [58] have shown to not affect growth of tilapia. Although improved growth has been linked to the production of digestive enzymes stimulated by probionts as reported earlier, metabolite production and improved nutrient utilization may also be responsible for improved feed efficiency and growth performance in tilapia fed probiotics. In most cases, the mechanism for improved growth performance is not known or reported. It is difficult to draw concrete conclusions and provide specific recommendations on the effects of dietary probiotics on growth performance of tilapia given that the studies vary widely with regard to fish age and size, stocking density, diet composition, dietary probiont concentration, feed allowances, feeding duration, and of course, type and source of probiont. However, early studies suggest dietary probiotic 
supplementation may have beneficial effects when used as growth promoters in tilapia. Furthermore, use of probiotics may allow for the improved utilization of difficult to digest dietary ingredients and nutrients in some fish species. For example, in ruminant and nonruminant mammals, use of a probiotic that produces high levels of cellulases allows for the increased use of high-cellulose carbohydrate sources [59]. This approach may prove useful in fish to overcome poor digestibility and anti-nutritional factors in plant-based alternative feed ingredients.

\section{Immunity and probiotics}

There is ample evidence to suggest that probiotics supplemented individually or in combination can enhance systemic and local gut immunity and disease resistance in tilapia (Table 2 included as supplementary data). In most studies, there appear to be some positive effect on either immune function, disease resistance, or both. Variation between studies is likely due to differences in the choice of probiont, dietary concentration, species strain and age/size of fish, feeding management and duration, dosage and virulence of challenge pathogen, and method of challenge. Other factors, such as environmental conditions, handling practices, and stocking densities, may also affect results. All these factors can influence the success or failure of dietary probiotics to affect immunity and/or disease resistance in fish. Furthermore, Merrifield et al. [11] suggests the success or potential of probiotics in many studies to prevent disease may be greater than the results show due to the use of intraperitoneal (IP) method of disease challenge. The IP method bypasses one of the most important ways probiotics can prevent infection: competitive exclusion in the GI tract. Intraperitoneal challenges do not reflect the effect of probiotics on resistance to infection - they demonstrate the effect of probiotics on infected fish [11]. In studies where disease resistance is improved, this suggests that the probiotic may be providing immune stimulation outside the GI tract. This is an important point to highlight in the application of probiotics to boost immunity of tilapia, because the vast majority of challenges performed in tilapia research studies are done by IP injection. Streptococcal disease, caused predominantly by Streptococcus iniae, is the biggest disease problem in tilapia culture [60]; however, it is difficult to reproduce reliably by bath immersion, so researchers have had to rely on IP injection to produce reliable, consistent infection generating the desired mortality rate. A degree of caution should be taken when attempting to apply the results of studies employing IP injection for disease challenge. However, as will be noted, the immune response outside the GI tract is enhanced in many probiotic studies, and probiont colonization of the gut may not be required to prevent infection.

\section{Immune function enhancement}

A large number of probiotic studies have been conducted in fish examining immune function and disease resistance, but their effects on immunity are hard to elucidate [11]. Certainly, it has been shown that one of the means by which probiotic microorganisms can boost immunity is by antagonistic colonization of the GI tract. However, the effect of the gut microbiota, and therefore probiont colonization, on the immune system is more far-reaching and complex than simple physical displacement of pathogenic microbes in the gut. Along with providing a physical barrier, the epithelium and gut-associated lymphoid tissue (GALT) interact with gut microbes to develop a complex immune response, involving the production of cytokines, chemokines, and different effector and regulatory T-cells [61]. In mammals, the gut microbiota also regulates immune gene expression of goblet cells, modifies glycosylation patterns (potentially affecting bacterial adhesion) [62], induces secretion of antimicrobial peptides [63], and ensures proper maturation of the GALT [61]. Although the level of GALT organization in fish is lower than in mammals, the GI microbiota is involved in epithelial differentiation and maturation in gnotobiotic studies in fish [17] and likely helps in GALT development. Nayak [16] also points out that probiotics interact with fish GALT to induce the immune response, increasing Ig+ cells, acidophilic granulocytes, and T-cell counts. Few studies in fish have focused on the effects of probiotic supplementation on gut immunity, and in tilapia, there are far fewer. Pirarat et al.[64] (in press) found an increase in the number of mucous cells in the distal portion of the intestine and a greater abundance of intraepithelial lymphocytes and acidophilic granulocytes in Nile tilapia fed diets containing Lactobacillus rhamnosus GG. No disease challenge was performed in the study. Although Ferguson et al. [34] did not find any changes in the number of leucocytes infiltrating the intestinal epithelium, blood leucocyte numbers and serum lysozyme activity were enhanced in Nile tilapia given the probiotic Pediococcus acidilactici.

Probiotic supplementation also improves the systemic immune response in fish. The process and mechanism in which probiotics in the gut stimulate the systemic response are not completely understood in mammals and are clearly undefined in fish. In mammals, the general consensus is that cells in the GALT process and recognize antigens via pattern recognition receptors, such as toll-like receptors (TLRs) [61]. The TLRs activate immune signaling pathways leading to the production of cytokines and other chemical signals which recruit immune cells (T-cells, natural killer or NK cells, neutrophils, etc.) and affect other immune functions. In tilapia, dietary supplementation of L. rhamnosus GG causes an increase in serum complement activity and enhanced phagocytosis and killing ability of head kidney leukocytes [36]. The authors suggest that L. rhamnosus GG in the gut affected these peripheral immune responses through an increase in the expression of tumor necrosis factor- $\alpha$ (TNF- $\alpha$ ) and interleukin-1 (IL-1). A number of other systemic, non-specific immune functions have been shown to be enhanced by dietary probiotic supplementation, including lysozyme activity, peripheral blood immune cell counts, alternative complement activity, phagocytic ability of leucocytes, neutrophil migration and adherence, plasma bactericidal activity, respiratory burst, myeloperoxidase, and superoxide dismutase activities, and others (Table 2 included as supplementary data). However, not all studies result in enhanced immune function. Shelby et al. [58] did not find any affect on lysozyme activity, alternative complement, or total serum immunoglobulin in tilapia fed commercial probiotics containing B. subtilis + B. licheniformis P. acidilactici, and S. cerevisiae. There is far less evidence available suggesting that dietary probiotics influence the humoral immune response in tilapia. Shelby et al. [58] did not find an effect of dietary probiotic supplementation on the antibody response to $S$. iniae. Probiotic use can enhance the immune response of tilapia, and this has been linked to improved disease resistance.

\section{Disease prevention}

Although it is important to understand how immune function is affected by probiotic supplementation, tilapia culturists are likely more interested in whether probiotics will prevent disease in fish. The success of probiotic use on disease prevention in fish has been mixed, but overall appears to be fairly effective in tilapia using a variety of probionts against a number of different bacterial pathogens (Table 2 included as supplementary data). Streptococcus iniae, Aeromonas hydrophila, and E. tarda are the primary bacterial pathogens that have 
been evaluated in tilapia probiotic studies. All but one study examining the effects of probiotics on disease resistance of tilapia used challenge by IP injection, which as outlined above, bypasses the gut and integument, and may not fully evaluate the potential of probiotics to prevent disease in tilapia. The effectiveness of probiotics in terms of protection against infection is often attributed to enhanced immunity. Pirarat et al. [64] has suggested that L. rhamnosus GG protection against E. tarda is accomplished by enhancing the alternative complement system thereby increasing phagocytic cell aggregation and phagocytic activity. As noted previously, the interaction of probiotics and the immune system is complex and identifying the exact immune mechanism(s) providing protection would be a difficult task. Probiotics can also be ineffective in preventing disease in tilapia. Shelby et al. [58] found that feeding commercial probiotics for 94 days did not prevent streptococcal disease. Probiotics have proven effective in preventing viral diseases in several fish species. Resistance of grouper (Epinephelus coiodes) to iridovirus is enhanced with supplementation of Lactobacillus plantarum in diet [65], and Pseudomonas sp., Vibrio sp., Aeromonas sp., and groups of coryneforms show antiviral activity to infectious hematopoietic necrosis virus (IHNV) [66]. Probiotic bacteria have also exhibited antiviral activity against poliovirus [67] and Oncorhynchus masou virus (OMV) [68] in fish. However, to our knowledge, the effect of probiotics has not been evaluated on any viral disease in tilapia.

Several factors affect the efficacy of probiotics on disease prevention in fish, especially the type of probiont and dietary dose concentration (dietary concentration + feeding duration). In tilapia, short-term feeding ( 2 weeks) and long-term ( 2 months or greater) have all proven to be effective in enhancing disease resistance in tilapia (Table 2 included as supplementary data). Few tilapia studies have explored the effects of dose concentration, although several have examined the effect of dietary concentration and feeding duration separately. Published information on immunostimulants suggests that, the larger the dose concentration, the less effective immunostimulants are in protecting fish against infection and can even result in immune suppression [5,11]. Little data exist to confirm whether this phenomenon also occurs with probiotic supplementation in fish diets, and no studies are known to have investigated the effects of pulsed-feeding (short-term, alternating feeding intervals of basal and probiotic diets) in tilapia, a method commonly used to prevent immune-suppression from excessive dose concentration when feeding immunostimulants to fish [11]. Aly et al. [54] found that supplementing Bacillus pumilus at $10^{12} / \mathrm{g}$ diet increased protection of Nile tilapia against $A$. hydrophila after 1 and 2 but not 8 months of feeding. The lower dietary concentration tested $\left(10^{6} / \mathrm{g}\right)$ did not provide any protection. In another study, Aly et al. [55] also found that dietary supplementation of L. acidophilus, B. subtilis, or a mixture of the two generally provided greater protection against A. hydrophila, P. fluorescens, and S. iniae after 2 months of feeding compared to 1 month. The form of probiotic administration can also impact effectiveness in affecting fish health. Improving viability of probionts during the feed making process and during feed storage can be improved by encapsulation in non-nutritive matrices, such as calcium alginate. Encapsulation of Shewanella putrefaciens in calcium alginate improved viability of the bacterium during feed storage, and its presence was found in the gastrointestinal track of Sengalese sole (Solea senegalensis) fed encapsulated but not non-encapsulated of S. putrefaciens [69]. Furthermore, the rout of probiotic administration can also affect the success of probiotic application. Addition of Lactococcus lactis RQ516 to rearing water increases the resistance of Nile tilapia to A. hydrophila [13]. Further research on the effects of dose dependency and form and route of probiont administration on disease resistance are needed for all fish species, including tilapia, in order to provide effective feeding and treatment regimens.

The combination of probiotics and prebiotics, also referred to as synbiotics, has shown promise in treating diseases in humans [70] and other mammals [71]. The prebiotic is thought to give a probiont a competitive advantage by providing a fermentable energy source enabling it to out-compete endogenous microbial populations [11,72] The survival rate of probiotics is improved during their passage through the digestive tract, thereby contributing to the stabilization and/or enhancement of the probiotic effects. Few studies have examined the effects of a synbiotic approach on the health of fish. Japanese flounder fed a diet containing Bacillus clausii or in combination with prebiotics fructo- or mannan oligosaccharide showed improved non-specific immune function [73]. Although the diet containing either prebiotic with $B$. clausii exhibited the highest immune function, activity was not significantly different compared to flounder fed $B$. clausii alone. No disease challenge was conducted in the study. Feeding a synbiotic combination of mannan oligosaccharide and Enterococcus faecalis improved survival of rainbow trout challenged with V. anguillarum than trout fed the individual prebiotic or probiotic [74]. Given the success observed with synbiotic approaches in mammals, a high priority should be given in future research in tilapia and other fish species.

\section{Conclusions and recommendations}

Research on the effect of probiotics on the health and growth of tilapia has increased significantly over the past few years, but many questions remain unanswered and more work needs to be conducted. Little effort has been undertaken to determine the microbial composition of the GI tract of tilapia. This basic information is vital to discovery and selection of potential probionts. Understanding the underlying mechanisms in which probionts are able to colonize the gut and alter the gut environment to influence digestion, nutrient absorption, growth performance, and immunity are also important for choosing potential microbes for use as probionts. Work in this area needs to continue and be expanded. Furthermore, insight as to how changes in the rearing environment and alterations of diet influence the gut microbial community will also help researchers and culturists select microbes with a better chance for success and to develop more effective feeding regimens and diet formulations. Use of probiotic mixtures containing several probionts may be required when this information is not available. Development of synbiotic mixtures may prove to be the most effective means of probiotic use, allowing fish culturists to control and provide favorable conditions in the gut and also ensure that a beneficial probiont is present and in sufficient numbers. The success of probiotic dietary supplementation to improve the health and growth performance of tilapia is encouraging given the small amount of research that has occurred. Their effectiveness will surely continue to improve as more questions and uncertainty surrounding probiotic use in tilapia diets are addressed. Future work must focus on applications of probiotics in order to achieve the maximum efficiency, and probiotic treatments must be used in concert with effective farm management and husbandry.

\section{References}

1. Lim C, Webster CD (2006) Tilapia biology, culture, and nutrition. The Haworth Press, Inc., Binghamton, NY.

2. Fitzsimmons K (2006) Prospect and potential for global production. Pages 51 72 in C. Lim and C.D. Webster, Editors. Tilapia: Biology, Culture and Nutrition. The Haworth Press, Inc., Binghamton, New York, NY

3. Li P, Gatlin DM (2005) Evaluation of the prebiotic GroBiotic $(-A$ and brewers yeast as dietary supplements for sub-adult hybrid striped bass (Morone 
chrysops $x$ M. saxatilis) challenged in situ with Mycobacterium marinum Aquaculture 248: 197-205.

4. FAO (Food and Agriculture Organization of the United Nations), 2002. Antibiotics residue in aquaculture products. Pages 74-82 in The State of World Fisheries and Aquaculture, Rome, Italy.

5. Sakai M (1999) Current research status of fish immunostimulants. Aquaculture 172: 63-92.

6. Gannam AL, Schrock RM (2001) Immunostimulants in fish diets. Pages 235266 in C. Lim and C.D. Webster, Editors. Nutrition and fish health. Food Product Press, New York, NY.

7. Irianto A, Austin B (2002) Probiotics in Aquaculture. J Fish Diseases 25: 633642

8. Gatesoupe FJ (2005) Probiotics and prebiotics for fish culture, at the parting of the ways. Aqua Feeds: Formulation \& Beyond 2: 3-5.

9. Kesarcodi-Watson A, Kasper H, Lategan MJ, Gibson L (2008) Probiotics in Aquaculture: The need, Principles and mechanisms of action and screening processes. Aquaculture 274: 1-14

10. Wang YB, Li JR, Lin J (2008) Probiotics in aquaculture: Challenges and outlook. Aquaculture 281: 1-4

11. Merrifield DL, Dimitroglou A, Foey A, Davies SJ, Baker RTM, et al. (2010a) The current status and future focus of probiotic and prebiotic applications for salmonids. Aquaculture 302: 1-18

12. Ringø E, Oldsen RE, Gifstad TO, Dalmo RA, Amlund H, et al. (2010) Prebiotics in aquaculture: review. Aquaculture Nutr 16: 117-136.

13. Zhou X, Wang Y, Jiangtao Y, Li W (2010) Inhibition ability of probiotic, Lactococcus lactis, against $A$. hydrophila and study of its immunostimulatory effect in tilapia (Oreochromis niloticus). Int J Engin Sci Tech 2: 73-80.

14. Fuller R (1989) Probiotics in man and animals. J Appl Bacteriol 66: 365-378.

15. Zhou Q, Li K, Jun X, Bo L (2009b) Role and functions of beneficia microorganisms in sustainable aquaculture. Bioresour Technol 100: 37803786 .

16. Nayak SK (2010a) Probiotics and immunity: a fish perspective. Fish \& Shellfish Immunol 29: 2-14.

17. Nayak SK (2010b) Role of gastrointestinal microbiota in fish. Aquac Res 41: 1553-1573.

18. Ringø E, Løvmo L, Kristiansen M, Bakken Y, Salinas I, et al. (2009) Lactic acid bacteria vs. pathogens in the gastrointestinal tract of fish: a review. Aquac Res 41: 451-467.

19. Sakata T, Sugita H, Mitsuoka T, Kakimoto D, Kadota H (1980a) Isolation of obligate anaerobes from the intestinal tracts of freshwater fish. Bull Jap Soc Sci Fish 46: 511

20. Sakata T, Okabayashi J, Kakimoto D (1980b) Variations in the intestina microflora of tilapia reared in fresh and sea water. Bull Jap Soc Sci Fish 46: 313-317

21. Sugita H, IsidaY, Deguchi Y, Kadota H (1982a) Bacterial flora in the gastrointestine of Tilapia nilotica adapted in sea water. Bull Jap Soc Sci Fish 48: 987-991.

22. Sugita H, Enomoto A, Deguchi $Y(1982 b)$ Intestinal microflora in the fry of Tilapia mossambica. Bull Jap Soc Sci Fish 48: 875

23. Sugita H, Oshima K, Tamura M, Deguchi Y (1983) Bacterial flora in the gastrointestine of freshwater fishes in the river. Bull Jap Soc Sci Fish 49: $987-$ 991.

24. Sugita H, Tokuyama K, Deguchi Y (1985) The intestinal microflora of carp Cyprinus carpio, grass carp Ctenopharyngodon idella and tilapia Sarotherodon niloticus. Bull Jap Soc Sci Fish 50: 1325-1329.

25. Sugita H, Tsunohara M, Fukumoto M, Deguchi $Y$ (1987) Comparison of microflora between intestinal contents and fecal pellets of fresh water fishes. Nippon Suisan Gakkaishi 53: 287-290

26. Tsuchiya C, Sakata T, Sugita H (2008) Novel ecological niche of Cetobacterium somerae, an anaerobic bacterium in the intestinal tracts of freshwater fish. Lett Appl Microbiol 46: 43-48.
27. Al-Harbi AH, Uddin N (2003) Quantitative and qualitative studies on bacterial flora of hybrid tilapia (Oreochromis niloticus $x$ O. aureus) cultured in earthen ponds in Saudi Arabia. Aquac Res 34: 43-48.

28. Al-Harbi $\mathrm{AH}$, Uddin $\mathrm{MN}$ (2004) Seasonal variation in the intestinal bacteria flora of hybrid tilapia (Oreochromis niloticus $x$ Oreochromis aureus) cultured in earthen ponds in Saudi Arabia. Aquaculture 229: 37-44.

29. Al-Harbi AH, Uddin N (2005) Bacterial diversity of tilapia (Oreochromis niloticus) cultured in brackish water in Saudi Arabia. Aquaculture 250: 566-572.

30. Molinari LM, Scoaris D, de O, Pedroso RB, Bittencourt N, et al. (2003) Bacterial microflora in the gastrointestinal tract of Nile tilapia, Oreochromis niloticus cultured in a semi-intensive system. Acta Scientiarum Biological Sciences Maringa 25: 267-271.

31. Heikkinen J, Vielma J, Kemilainen O, Tiirola M, Eskelinen P, et al. (2006) Effects of soybean meal based diet on growth performance, gut histopathology and intestinal microbiota of juvenile rainbow trout (Oncorhynchus mykiss) Aquaculture 261: 259-268.

32. Timmerman HM, Koning CJM, Mulder L, Rombout FM, Beynen AC (2004) Monostrain, multistrain and multispecies probiotics - a comparison of functionality and efficacy. Int J Food Microbiol 96: 219-233.

33. Marzouk MS, Moustafa MM, Mohamed NM (2008) The influence of some probiotics on the growth performance and intestinal microbial flora of Oreochromis niloticus. Proceedings of 8th International Symposium on Tilapia in Aquaculture, Cairo, Egypt, pp. 1059-1071.

34. Ferguson RMW, Merrifield DL, Harper GM, Rawling MD, Mustafa S, et al. (2010) The effect of Pediococcus acidilactici on the gut microbiota and immune status of on-growing red tilapia (Oreochromis niloticus). J Applied Microbiol 109: 851-862.

35. Bates JM, Mittge E, Kuhlman J, Baden KN, Cheesman SE, et al. (2006) Distinct signals from the microbiota promote different aspects of zebrafish gut differentiation. Dev Biol 297: 374-386

36. Pirarat N, Pinpimai K, Endo M, Katagiri T, Ponpornpisit A, et al. (2011) Modulation of intestinal morphology and immunity in Nile tilapia (Oreochromis niloticus) by Lactobacillus rhamnosus GG. Res Vet Sci 91: e92-e97 (In press).

37. Merrifield DL, Harpr G, Baker RTM, Ringø E, Davies S J (2010b) Possible influence of probiotic adhesion to intestinal mucosa on the activity and morphology of rainbow trout (Oncorhynchus mykiss) enterocytes. Aquacult Res 41: $1268-1272$

38. Lovell T, Limsuwan T (1982) Intestinal synthesis and dietary non essentiality of vitamin $B_{12}$ for Tilapia nilotica. Trans of Amer Fish Soc 11: 485-490.

39. Sugita H, Miyajima C, Deguchi $Y(1990)$ The vitamin $B_{12}$ producing ability of the intestinal bacteria isolated from tilapia and channel catfish. Nippon Suisan Gakkaishi 56: 701.

40. Sugita H, Miyajima C, Deguchi $Y$ (1991) Vitamin $B_{12}$ producing ability of the intestinal microflora of freshwater fish. Aquaculture 92: 267-276.

41. Teshima S, Kashiwada K (1967) Studies on the production of B vitamins by intestinal bacteria of fish. 3. Isolation of vitamin $B_{12}$ synthesizing bacteria and their bacteriological properties. Bull Jap Soc Sci Fish 33: 979-983.

42. Merrifield DL, Bradley G, Harper GM, Baker RTM, Munn CB, et al. (2011) Assessment of the effects of vegetative and lyophilised Pediococcus acidilactici on growth, feed utilisation, intestinal colonisation and health parameters of rainbow trout (Oncorhynchus mykiss Walbaum). Aquac Nutr 17: 73-79.

43. Ghazalah AA, Ali HM, Gehad EA, Hammouda YA, Abo-State HA (2010) Effect of probiotics on performance and nutrients digestibility of Nile tilapia (Oreochromis niloticus) fed low protein diets. Nature and Sci 8: 46-53.

44. Newsome SD, Fogel ML, Kelly L, Martinez del Rio C (2011) Contributions of direct incorporation from diet and microbial amino acids to protein synthesis in Nile tilapia. Funct Ecol 25: 1051-1062 (in press).

45. Kihara M, Sakata T (1997) Fermentation of dietary carbohydrates to shortchain fatty acids by gut microbes and its influence on intestinal morphology of a detritivorous teleost tilapia (Oreochromis niloticus). Com Biochem Physiol 118 : 1201-1207.

46. Smith TB, Wahl DH, Mackie RI (2005) Volatile fatty acids and anaerobic fermentation in temperate piscivorous and omnivorous freshwater fish. J Fish Biol 48: 829-841. 
47. Honsheng M (2010) Effects of probiotics on activities of digestive enzyme for tilapia. J South China Normal Univ 2: 10-15.

48. Essa MA, El-Serafy SS, El-Ezabi MM, Daboor SM, Esmael NA, et al. (2010) Effect of different dietary probiotics on growth, feed utilization and digestive enzymes activities of Nile tilapia, Oreochromis niloticus. J Arabian Aquacult Soc 5: 143-161.

49. Lara-Flores M, Olvera-Novoa MA, Guzmán-Méndez BE, López-Madrid W (2003) Use of the bacteria Streptococcus faecium and Lactobacillus acidophilus, and the yeast Saccharomyces cerevisiae as growth promoters in Nile tilapia (Oreochromis niloticus). Aquaculture 216: 193-201.

50. Lara-Flores M, Olivera-Castillo L, Olvera-Novoa MA (2010) Effect of the inclusion of a bacterial mix (Streptococcus faecium and Lactobacillus acidophilus), and the yeast (Saccharomyces cerevisiae) on growth, feed utilization and intestinal enzymatic activity of Nile tilapia (Oreochromis niloticus). Internat J Fish Aquaculture 2: 93-101.

51. Gawlicka A, Parent B, Horn MH, Ross N, Opstad I, et al. (2000) Activity of digestive enzymes in yolksac larvae of Atlantic halibut (Hippoglossus hippoglossus): Indication of readiness for first feeding. Aquaculture 184: 303314.

52. German DP, Horn MH, Gawlicka A (2004) Digestive enzyme activities in herbivorous and carnivorous prickleback fishes (Teleostei: Stichaeidae): Ontogenetic, Dietary, and Phylogenetic Effects. Physiol Biochem Zool 77: 789804

53. El-Rhman AMA, Khattab YA, Shalaby AM (2009) Micrococcus luteus and Pseudomonas species as probiotics for promoting the growth performance and health of Nile tilapia, Oreochromis niloticus. Fish Shellfish Immuol 27: 175-180.

54. Aly SM, Abdel-Galil Ahmed Y, Abdel-Aziz Ghareeb A, Mohamed MF (2008a) Studies on Bacillus subtilis and Lactobacillus acidophilus, as potential probiotics, on the immune response and resistance of Tilapia nilotica (Oreochromis niloticus) to challenge infections. Fish Shellfish Immunol 25: 128-136.

55. Aly SM, Mohamed MF, John G (2008b) Effect of probiotics on the survival, growth and challenge infection in Tilapia nilotica (Oreochromis niloticus). Aquac Res 39: 647-656.

56. El-Haroun ER, Goda AMA-S, Kabir Chowdhury MA (2006) Effect of dietary probiotic biogens supplementation as a growth promoter on growth performance and feed utilization of Nile tilapia Oreochromis niloticus (L.). Aquac Res 37 1473-1480.

57. Mehrim Al (2009) Effect of dietary supplementation of Biogen (commercial probiotic) on mono-sex Nile tilapia Oreochromis niloticus under different stocking densities. J Fish Aquat Sci 4: 261-273.

58. Shelby RA, Lim CE, Aksoy M, Klesius PH (2006) Effect of probiotic diet supplements on disease resistance and immune response of young Nile tilapia, Oreochromis niloticus. J Appl Aquac 18: 23-34

59. Ushakova NA, Kotenkova EV, Kozlova AA, Nifatov AV (2006) A study of the mechanisms of probiotic effect of Bacillus subtilis Strain 8130. Appl Biochem Microbiol 42: 252-257.

60. Shoemaker C, Lim C, Yildirim-Aksoy M, Welker T, Klesius PH (2006) Growth response and acquired resistance of Nile tilapia, Oreochromis niloticus (L.) that survived Streptococcus iniae infection. Aquac Res 37: 1238-1245.

61. Sanz Y, De Palma G (2009) Gut microbiota and probiotics in modulation of epithelium and gut-associated lymphoid tissue function. Int Rev Immunol 28: $397-413$

62. Caballero-Franco C, Keller K, De Simona C, Chadee K (2007) The VSL\#3 probiotic formula induces mucin gene expression and secretion in colonic epithelial cells. Am J Physiol Gastrointest Liver Physiol 292: G315-G322.

63. Vaishnava S, Behrendt CL, Ismail AS, Eckmann L, Hooper LV (2008) Paneth cells directly sense gut commensals and maintain homeostasis at the intestinal host-microbial interface. Proc Natl Acad Sci USA 105: 20858-20863.

64. Pirarat N, Kobayashi T, Katagiri T, Maita M, Endo M (2006) Protective effects and mechanisms of a probiotic bacterium Lactobacillus rhamnosus against

This article was originally published in a special issue, Probiotic \& Prebiotic Applications in Aquaculture handled by Editor(s). Dr. Daniel L. Merrifield, University of Plymouth, UK; Prof. Zhigang Zhou, Chinese Academy of Agricultural Sciences, China experimental Edwardsiella tarda infection in tilapia (Oreochromis niloticus). Vet Immunol Immunopathol 113: 339-347.

65. Son VM, Chang CC, Wu MC, Guu YK, Chiu CH, et al. (2009) Dietary administration of the probiotic, Lactobacillus plantarum, enhanced the growth innate immune responses, and disease resistance of the grouper Epinephelus coioides. Fish Shellfish Immunol 26: 691-698.

66. Kamei Y, Yoshimizu M, Ezura Y, Kimura T (1988) Screening of bacteria with antiviral activity from fresh water salmonid hatcheries. Microbiol Immunol 32 67-73.

67. Girones R, Jofre JT, Bosch A (1989) Isolation of marine bacteria with antivira properties. Can J Microbiol 35: 1015-1021.

68. Direkbusarakom S, Yoshimizu M, Ezura Y, Ruangpan L, Danayadol Y (1998) Vibrio spp. the dominant flora in shrimp hatchery against some fish pathogenic viruses. J Mar Biotechnol 6: 266-267.

69. Rosas-Ledesma R, León-Rubio JM, Alarcón FJ, Moriñgo MA, Balebona MC (2011) Calcium alginate capsules for oral administration of fish probiotic bacteria: assessment of optimal conditions for encapsulation. Aquac Res. doi:10.1111/j.1365-2109.2011.02809.x

70. Haskey N, Dahl WJ (2006) Synbiotic therapy: a promising new adjunctive therapy for ulcerative colitis. Nutr Rev 64: 132-138.

71. Zimmerman B, Bauer E, Mosenthin R (2001) Pro- and prebiotics in pig nutrition - potential modulators of gut health? J Animal Feed Sci 10: 47-56.

72. Gibson GR, Roberfroid MB (1995) Dietary modulation of the human colonic microbiota: introducing the concept of prebiotics. J Nutr 125: 1401-1412.

73. Ye J-D, Wang K, Li F-D, Sun Y-Z (2011) Single or combined effects of fructoand mannan oligosaccharide supplements and Bacillus clausii on the growth feed utilization, body composition, digestive enzyme activity, innate immune response and lipid metabolism of the Japanese flounder Paralychthys olivaceus. Aquac Nutr 17: e902-e911.

74. Rodriguez-Estrada U, Satoh S, Haga Y, Fushimi H, Sweetman J (2009) Effects of single and combined supplementation of Enterococcus faecalis, mannan oligosaccharide and polyhydrobutyric acid on growth performance and immune response of rainbow trout Oncorhynchus mykiss. Aquac Sci 57: 609-617.

75. Ali HM, Ghazalah AA, Gehad EA, Hammouda YA, Abo-State HA (2010) Practica aspects and immune response of probiotics preparations supplemented to Nile tilapia (Oreochromis niloticus) diets. Nature and Sci 8: 39-45.

76. Galindo AB, Hartemink R, Schrama JW, Verreth J, Bucio L, et al. (2009) Kinetics of Lactobacillus plantarum 44a in the faeces of tilapia (Oreochromis niloticus) after its intake in feed. J Appl Microbiol 107: 1967-1975.

77. Jatoba A, Vieira FdN, Buglione-Neto CC, Mouriño' JLP, Silva BC, et al. (2011) Diet supplemented with probiotic for Nile tilapia in polyculture system with marine shrimp. Fish Physiol Biochem 37: 725-732. (in press).

78. Vijayabaskar P, Somasundaram ST (2008) Isolation of bacteriocin producing lactic acid bacteria from fish gut and probiotic activity against common fresh water fish pathogen Aeromonas hydrophila. Biotechnol 7: 124-128.

79. El-Ashram AMM, Mohammed MF, Aly SM (2008) Effect of Biobuds as a commercial probiotic product in cultured tilapia. $8^{\text {th }}$ International Symposium on Tilapia in Aquaculture. 1089-1096.

80. Aly SM, Abd-El-Rahman AM, John G, Mohamed MF (2008c) Characterization of some bacteria isolated from Oreochromis niloticus and their potential use as probiotics. Aquaculture 277: 1-6.

81. Taoka Y, Maeda H, Jo J-Y, Kim S-M, Park S-I, et al. (2006) Use of live and dead probiotic cells in tilapia Oreochromis niloticus. Fish Sci 72: 755-766.

82. Mohamed MH, Refat NAGA (2011) Pathological evaluation of probiotic, Bacillus subtilis, against Flavobacterium columnare in tilapia nilotica (Oreochromis niloticus) fish in Sharkia Governorate. Egypt J Amer Sci 7: 244-256. 